\title{
Notas Reflexivas: Kant, Freud e a Liberdade
}

\section{Reflective notes: Kant, Freud and freedom}

\section{Resumo}

Este capítulo tem a proposta de se apresentar como notas reflexivas, as quais venham contribuir para investigações que possam conectar preocupações filosóficas com conhecimentos originados em outras áreas. A título de reflexão inicial, por um lado, optamos por fazer um breve itinerário, colhendo impressões da filosofia kantiana em relação ao tema da liberdade, e, por outro, com a possibilidade de pensar essa mesma categoria no contexto teórico da psicanálise freudiana.

Palavras-chave: Kant, Freud, Liberdade, Filosofia, Psicanálise.

\section{Abstract}

This chapter has the proposal of presenting itself as some reflective notes, which may contribute to investigations that can connect philosophical concerns with knowledge originated in other areas. As an initial reflection, on the one hand, we chose to make a brief itinerary, taking impressions of Kantian philosophy on the subject of freedom, and, on the other, with the possibility of thinking that same category in the theoretical context of Freudian psychoanalysis.

Keywords: Kant, Freud, Freedom, Philosophy, Psychoanalysis.

\section{Introdução}

Qual o objetivo de um artigo, texto ou ensaio? Instruir? Provocar discussões? Apresentar discussões? Servir como base para reflexões futuras? Sejam por parte do autor ou do possivel leitor?

No final, toda produção textual se presta um pouco a todas essas possibilidades, variando quanto à medida. De nossa parte, escrevemos estas "Notas" para retomar de uma forma um pouco mais elaborada um dos primeiros problemas filosóficos que nos chamaram à atenção quando começamos a estudar Filosofia. Assim, esperamos que, em alguma medida, as linhas deste capítulo também possam servir para suscitar algumas reflexões, principalmente, por parte 
de leitores que estejam iniciando os seus estudos filosóficos.

Um dos temas que nos cativou nos anos de iniciação fora a questão da Liberdade.

A pergunta sobre a liberdade é mais complexa do que pode parecer à primeira vista. Quando formulada em um instante inicial parece restringir-se a tudo aquilo que podemos ou não fazer. A indagação colocada nesses termos: "Poder ou não Poder"; conduz o pensamento a uma rede de conceitos: poder, ação, vontade, determinação, restrição etc. - apenas para citar alguns. Em verdade, poder agir de uma determinada maneira, ou não, invoca também a dimensão da alteridade, pois qual é a participação do outro em nossas ações? É tão somente objeto de nossas afecções? Ou ao contrário, é do outro que emanam inibições, restrições às nossas ações, tanto na forma de normativa quanto até objetiva?

Embora possa ser iniciada por múltiplos questionamentos, uma reflexão não deveria ficar refém desse emaranhado; é preciso escolher um "ângulo de ataque", privilegiar uma linha de investigação, ao menos inicialmente, quiçá, prosseguir por outros caminhos em momentos futuros - ou em novas "notas".

Isto colocado, começaremos com Kant, o velho sábio de Königsberg, cujo raciocínio dotado de poderosa lógica nos legou uma obra densa, de prosa por vezes árida no estilo, mas nem por isso menos brilhante. Façamos justica a uma obra que, apesar da complexidade, promove também passagens de muita beleza, como neste trecho em que inicia a sua conclusão da Crítica da razão prática:

Duas coisas enchem o ânimo de admiração e veneração sempre nova e crescente, quanto mais frequente e persistentemente a reflexão ocupa-se com elas: o céu estrelado acima de mim e a lei moral em mim. Não me cabe procurar e simplesmente presumir ambas como envoltas em obscuridade, ou no imediatamente transcendente além de meu horizonte; vejo-as ante mim e conecto-as imediatamente com a consciência de minha existência [...] (KANT, 2015, p. 191).

Muito embora o pensamento de Kant nos instigue a ir adiante em nossa reflexão, por vezes o pensamento pode recuar estrategicamente, para depois avançar. Neste caso, o recuo é na própria cronologia kantiana, mais precisamente para a obra que lançou o filósofo de língua alemã para a posteridade filosófica, a saber, à Crítica da razão pura.

Nessa primeira crítica, Kant se preocupa com o conhecimento, ou ainda, com a nossa capacidade de conhecer as coisas, ou mais precisamente com os limites de nossa capacidade em conhecer as coisas. É lá que pela primeira vez aparece a questão da liberdade, sendo esta colocada enquanto um problema cosmológico:

[...] entendo por liberdade, em sentido cosmológico, a faculdade de iniciar por si um estado, cuja causalidade não esteja, por sua vez, subordinada, segundo a lei natural, a outra causa que a determine quanto ao tempo. A liberdade é, neste sentido uma ideia transcendental pura que, em primeiro lugar, nada contém extraído da experiência e cujo objeto, segundo lugar, não pode ser dado de maneira determinada em nenhuma experiência, porque é uma lei geral, até da própria possibilidade de toda a experiência, que tudo o que acontece deva ter uma causa e por, conseguinte, também a causalidade da causa, uma causa [...] porém desse modo, não se pode obter a totalidade absoluta das condições na relação causal, a razão cria a ideia de uma espontaneidade na relação causal [...] (KANT, 1994, p. 463, grifo nosso).

É no interior da Crítica da razão pura que Kant estabelece o pressuposto de um idealismo transcendental, o qual retiraria a razão do labirinto da tradição metafísica, que busca o conhecimento de coisas que estariam para além do tempo e espaço, portanto, fora da experiência sensível, tais como Deus, a alma e a própria liberdade, pois se tratam de conceitos que ora se identificam, ora 
dependem da possibilidade do incondicionado. Ou seja, para apreender os sentidos de Deus, da alma ou liberdade precisaríamos conhecer a natureza de uma série causal infinita e/ou mesma eterna. Porém, e essa é uma das argumentações na Crítica..., somos seres finitos, cognitivamente limitados a apreender - enquanto experiência aquilo que nos chega categorizado em tempo e espaço. O que está para além do espaço e tempo é o suprassensível, o noumenico ou a coisa em si, a qual não conseguimos acessar pela experiência - podemos pensá-la, mas não a conhecer. Já aquilo que conhecemos: o fenomênico, pode ser apreendido por chegar até nós categorizado espacial e temporalmente.

A admissão dessa distinção abre espaço para se pensar, por um lado, o domínio de uma liberdade transcendental "[...] legitimamente pensada como necessária em virtude da exigência da razão pelo incondicionado [...]" (ARAÚJO, 2012, p. 37) - o incondicionado pode ser pensado, mas não conhecido diretamente pela experiência e, portanto, não pode ser dissecado do ponto de vista teórico - e, por outro lado, uma liberdade prática, a qual atuaria como uma propriedade da vontade e, desta forma, colocar-se-ia distinta dos dilemas cosmológicos em torno do incondicionado.

A liberdade prática se articula com o conceito de livre arbítrio que, de acordo com Kant (1994, p. 463):

A liberdade no sentido prático é a inde-
pendência do arbítrio frente à coação dos
impulsos da sensibilidade. Na verdade,
um arbítrio é sensível, na medida em que
é patologicamente afetado (pelos móbiles
da sensibilidade); e chama-se animal (ar-
bitrium brutum) quando pode ser patolo-
gicamente necessitado. O arbítrio humano
é, sem dúvida, um arbitrium liberum por-
que a sensibilidade não torna necessária a
sua ação e o homem possui a capacidade
de determinar-se por si, independente-
mente da coação dos impulsos sensíveis.

Ou seja, o arbítrio humano é dividido em arbítrios livre e bruto. A capacidade de "determi- nar-se por si" presente no arbítrio livre sinaliza para um arbítrio em que a razão predomina, guia as escolhas; ao contrário das opções realizadas em submissão aos caprichos dos impulsos sensíveis. É o primeiro - arbítrio livre - que servirá de "pano de fundo" à moralidade. Eis, portanto, a "Lei moral em mim" que tanto fascinava o pensador de Königsberg...

Notemos que essa abordagem prenuncia uma situação conflitiva entre a consciência guiada racionalmente pela lei moral, e as "deturpações" incitadas pelos impulsos naturais - sensíveis.

Essa insinuação de conflito interior nos domínios do arbítrio, no coração da subjetividade, abre espaço para trazermos ao palco, antes do drama de encerramento, uma linha teórica diversa, distinta não apenas em suas formulações e metodologia, mas também por não se incluir voluntariamente no bojo das discussões filosóficas, ainda que várias de suas proposições, se aceitas, serviram - e ainda servem - de pontos de partida para interessantes especulações no campo da Filosofia. Referimo-nos à Psicanálise freudiana.

É do conhecimento dos mais diversos autores que se debruçaram sobre a literatura psicanalítica, que o doutor Sigmund Freud, parte por sua formação de médico neurologista, parte pela atmosfera acadêmica de Viena da virada do século XIX ao XX, tinha predileção declarada por um cientificismo mais alinhado ao positivismo da época, do que com escolas de pensamento mais eminentemente especulativas e frutos de um idealismo gerado no pensamento germânico. Ainda que, no final, a "Ciência da alma" não pudesse atender aos critérios rigorosos de uma "Ciência dura", tais como as Ciências Naturais.

Deixando de lado a discussão sobre critérios de cientificidade e mais ainda se a Psicanálise seria ou não Ciência - referir-nos-emos a essa como um saber -, concentrar-nos-emos no que o saber freudiano pode contribuir com uma discussão acerca do conflito interior do humano e como isso também subsidia discussões acerca da liberdade. 
Para começarmos, devemos assumir o contexto em que Freud desenvolveu o seu pensamento no espaço da clínica. O esforço do sábio vienense se voltava à busca da cura de algumas doenças que afligiam pacientes naquele final de século, quando o então jovem médico residente em Neurologia aprofundava os seus estudos.

Com o passar dos anos, Freud foi desenvolvendo um corpo teórico que buscava dar tanto o diagnóstico - explicar determinada condição patológica -, como o prognóstico - instruções para um tratamento que revertesse o quadro de patologia -, ambos considerando - de uma maneira inovadora à época - a chamada doenca mental. O curioso desse itinerário, que costuma ser pouco destacado, é que nos primórdios de suas formulações - bem de acordo com a abordagem médica da época - Freud tentou desenvolver um modelo de explicação que de alguma maneira se ancorasse em processos cerebrais! Porém, dado o pouco desenvolvimento da Neurologia naquele período, fez com que o médico vienense abandonasse esse caminho de buscar um início de uma série causal físico-biológica que explicasse o comportamento humano, trocando-a por um construto teórico que, em seu limite, operaria em um "como se", descrevendo a vida anímica do indivíduo com base em seus comportamentos emocionais, nos conflitos entre as necessidades primitivas, básicas, e uma forma de racionalidade estratégica, adquirida socialmente, que tentaria barrar a satisfação dessas necessidades ou, pelo menos, adiar a sua consumação.

A descrição dos caminhos teóricos freudianos nos tomaria tempo em demasia; Freud elaborou as suas teorias à medida que evoluíam as suas observações sobre as aflições de seus pacientes, por isso, algumas ideias, hipóteses e conceitos foram alterados ao longo dos anos; ênfases foram mudadas, a importância de determinados conceitos foi aprimorada. Não se trata, portanto, de uma teoria bem fechada e amarrada tal como se vê em alguns sistemas filosóficos.

Mesmo assim, precisamos discorrer ao menos sobre os aspectos mais gerais do que seria uma versão mais tardia dos conceitos freudianos para, então, aproveitá-los em nossa discussão.

Para Freud, todos os processos anímicos têm uma causa, mas essa série causal se limita à interioridade do indivíduo, às suas emoções, vivências desde a infância até a idade adulta.

O ser humano traz consigo necessidades biológicas, fome, sede, sono, impulso à reprodução, então chamadas de processos primários que vão se modelando ao longo da vida do indivíduo. Tal modelamento não segue uma fórmula fechada, totalmente definida; eis que entram as vivências, os traumas infantis, as interações com a família e sociedade. Assim, cada pessoa compartilha certos níveis de experiência comum: a linguagem, as tradições familiares, os valores morais, símbolos culturais etc. Contudo, a Psicanálise reconhece o indivíduo como singular, pois a forma como esses conteúdos compartilhados são efetivamente assimilados traz sutilezas únicas para cada um, e isso forja uma afinação ligeiramente diferente para cada pessoa no concernente aos processos secundários, que nada mais são do que os mecanismos mentais que criamos para gerenciar as próprias afecções, formulando, inclusive, estratégias distintas de como e quando adiarmos as nossas satisfações.

Como se organizam essas "estratégias de contenção"? Para o velho mestre vienense, o aparelho anímico se desenvolve por clivagem. No início, a psique se organiza ao longo do tempo por "camadas", "seções", "subsistemas", enfim, por "áreas funcionais", cada uma executando uma função que complementa o sistema anímico como um todo.

Do ponto de vista tópico - em uma descrição mais tardia - o ego (eu) seria a primeira instância da nossa personalidade, o nosso "eu consciente"; o superego, uma estrutura que agrega principalmente os valores culturais que assimilamos em nossas vivências, a Lei paterna em nós; por fim, o id (isso) corresponde à fonte das necessidades - desejos - em suas formas brutas, o canal pelo qual exigências de nossas necessidades biológicas ganham expressão psíquica - confira O ego e o id (FREUD, [20--?d]). 
Para compreender a proposta freudiana, é igualmente importante incluir a noção de catexia, ou investimento. Neste caso, as nossas necessidades biológicas, de alguma maneira, formam uma energia psíquica - sim, Freud "salta" uma teorização mais detalhada das relações mente-corpo, o que leva as formulações do vienense a serem classificadas como metabiológicas -; de qualquer maneira, a gestão dos investimentos - catexias - psíquicas por esses subsistemas - ego, superego, id - é a razão de ser e a maneira como funciona o nosso aparelho anímico, a nossa própria psique.

Em uma formulação já presente nos primórdios da Psicanálise, a nossa própria formação psíquica estaria subordinada a um princípio de evitação do desprazer:

Somos assim levados a concluir que essas liberações de prazer e desprazer regulam automaticamente o curso dos processos de catexização. No entanto, para possibilitar desempenhos mais delicadamente ajustados, fez-se depois necessário tornar o curso das representações menos dependente da presença ou da ausência de desprazer [...] (FREUD, 1988, p. 523).

Percebamos que aqui se insinua que toda a dinâmica psíquica inicialmente funciona de maneira "automática", tal como uma rede de arcos reflexos. Se o organismo tem sede, essa necessidade orgânica pressiona o psíquico que, de alguma maneira, fica tensionado por tal estímulo, tensão que é percebida como desprazer, logo, a psique busca formas de aliviar essa sensação incômoda; saciada a sede, a tensão é então aliviada, enquanto que o alívio da tensão é registrado pelo sistema como prazer. Agora, a memória passa a ter o registro de que "beber água" alivia o desprazer - dor - da sede.

Mas qual é o significado de se "possibilitar desempenhos mais delicadamente ajustados"?

A descrição que Freud faz, ao longo do capítulo VII de sua Interpretação dos sonhos, é que esse processo primário não funciona com tanta eficiência, afinal, o indivíduo, que agora possui uma imagem de satisfação - tal como no exemplo da sede - pode, em um processo puramente reflexivo dentro da mente em formação, ser levado a alucinar com a satisfação da sede quando estiver novamente pressionado pelo próprio corpo sobre eventual necessidade de água. Assim, como "ensinar" a mente de que a imagem da memória não substitui a necessidade de uma nova ação motora no mundo buscar agir para efetivamente beber a água?

Para Freud seríamos dotados - biologicamente? - da capacidade de desenvolver um processo que complementaria o funcionamento desse sistema primário:

Proponho descrever o processo psíquico admitido exclusivamente pelo primeiro sistema como "processo primário", e o processo que resulta da inibição imposta pelo segundo sistema, como "processo secundário". [...] $\bigcirc$ pensar, como um todo, não passa de uma via indireta que vai da lembrança de uma satisfação (lembranca esta adotada como uma representacão-meta) até uma catexia idêntica de mesma lembrança, que se espera atingir mais uma vez por intermédio das experiências motoras [...] (FREUD, 1988, p. 545).

Ou seja, para a Psicanálise é o nosso processo de pensar que inibe uma reação reflexa que seria ineficiente para alcançar os resultados dos quais dependem até mesmo a nossa própria sobrevivência. É o sistema de pensamento que auxilia na diferenciação entre uma lembrança de satisfação e a satisfação real. São tais inibições que nos forçam a buscar recriar ou reencontrar aquilo que foi representado como prazer - diferentemente de apenas ficarmos presos à própria lembrança -, ou seja, por meio dessas reminiscências buscamos alterar - de maneira favorável - a realidade ao nosso redor. Não para menos que ao longo de sua obra, Freud nomeou esse princípio mais estratégico - que redireciona as catexias em nossa mente, de maneira tal a "forçar" as ações motoras que realmente consigam a satisfação - de princípio de realidade. 
É claro que isso assume uma miríade incrível de sutilezas na medida em que adiar uma satisfação, mesmo que real e imediata, pode ser necessário para atender a exigências culturalmente adquiridas, até interiorizadas - memorizadas - no fundo de nossas personalidades. Desde a fonte do pensamento mágico infantil, que tem dificuldade em aceitar que as coisas do mundo ao redor se movem, modificam-se conforme regras próprias que são alheias à nossa vontade - por exemplo, não podermos simplesmente voar quando assim desejarmos. E que mais tarde, ora por tentativa e erro, ora aprendendo observando os adultos - vamos descobrindo os limites de nossa capacidade de alterar o mundo, desenvolvendo estratégias a partir disso. Passamos, então, por uma "constelação de conflitos" menores ou maiores de nossas vivências em sociedade, em que os nossos desejos devem ser equacionados pelos limites socialmente impostos - inclusive pela persona do outro que comumente terá intenções e desejos diferentes dos nossos.

Não podemos e/ou devemos impor ao outro a nossa vontade, porém, em alguns casos poderíamos dialogar - convencer pela linguagem racional - que a nossa ideia e/ou linha de ação talvez seja a melhor.

Assim, reencontramos na Psicanálise de Freud alguns aspectos interessantes para pensarmos a liberdade que, embora tenham sido gerados em outra perspectiva, podem convergir com algumas preocupações kantianas sobre o tema.

Ora, Kant nos apresenta um arbítrio livre, o qual deve ser racional e diferente do arbitrio bruto, este derivado da submissão patológica às necessidades sensíveis. Então, muito tempo antes e em um viés puramente filosófico, já encontrávamos o reconhecimento do conflito entre as nossas necessidades sensíveis - biológicas? - para aquilo que a racionalidade nos revela ser o mais adequado. Mais do que um conflito, o reconhecimento da presença dessas exigências nada racionais, as quais a racionalidade deveria fazer frente, e prevalecer.
Isso nos coloca em posição de trazermos para a discussão alguns termos que já se fazem presentes na obra kantiana e que podem posteriormente ser observados pelo ângulo mais freudiano.

Quando pensamos liberdade pela abordagem kantiana, surge em seu complemento a discussão acerca da autonomia e com esta a independência.

Como dissemos no início, esses questionamentos se prestam a uma variedade de perspectivas. Ao escolhermos avançar por um viés menos cosmogônico, vamos, de certa maneira, alinhando-nos a um olhar mais crítico sobre o problema - crítico aqui, no sentido kantiano, de delimitação - e abandonamos um pouco o impasse sobre séries causais infinitas que, assim como Kant, à sua própria maneira também fora feito na Psicanálise; aproximamo-nos de um composto que enlaça a filosofia prática e a clínica psicanalítica, com ressonâncias tanto do domínio da Ética como da Filosofia Política.

Do ângulo do mundo prático, Kant demarca uma fronteira conceitual, esse movimento do seu pensamento fundamenta, de um lado, o agir por autonomia, e por contraste, o agir por heteronomia. Quando agimos por heteronomia, o móbile - o motivo ou desencadeador - da ação é o objeto. Ou melhor, "devo fazer tal coisa, porque quero uma outra". Nesse contexto, o princípio desencadeador da ação nos é externo, vem de fora. Pode, portanto, assumir as mais diferentes formas: busca pelo reconhecimento, evitar uma punição, alcançar um resultado em benefício próprio - que para alguns se confunde com a procura da própria felicidade - etc., de modo que em todas essas situações as escolhas - arbítrio - servem a uma inclinação, estando condicionadas, podemos dizer, em maior ou menor grau, curvando-se às exigências do mundo sensível. Ou ainda, age-se por "pressão" da cultura, das expectativas do outro, enfim, sacrifica-se a pressuposição que deve estar presente em uma ação autônoma, que é a independência - confira Fundamentacão da metafísica dos costumes (KANT, 2005). 
Do outro lado da fronteira conceitual demarcada por Kant fica, então, a autonomia e com esta o princípio supremo da moralidade:

A autonomia da vontade é a constituição da vontade, graças a qual ela é para si mesma a sua lei (independentemente da natureza dos objetos do querer). O princípio da autonomia é, portanto, não escolher senão de modo a que as máximas da escolha no próprio querer sejam simultaneamente incluídas como lei universal [...] (KANT, 2005, p. 70)

A vontade autônoma kantiana está alinhada diretamente a um princípio de universalidade. No entendimento do pensador de Königsberg, a razão, enquanto pensamento lógico, não sofre variações ligadas à época ou localidade. Como seres racionais que somos, se nos deixássemos guiar exclusivamente por essa lógica, inequivocamente chegaríamos a conclusões comuns, universais; assim, seríamos capazes de articular parâmetros práticos ao nosso agir e que atenderiam unicamente aos móbiles dessa lógica, conduta racional passível de ser transformada em lei universal do agir, esta que seria o ponto comum isento ao relativismo das circunstâncias individuais e, portanto, expressão mais autêntica de um agir por independência, cuja força legisladora que aponta ao certo ou errado viria de nós mesmos - e não do mundo exterior ou de motivações egoístas, logo, livres.

Podemos perceber que no pensamento kantiano a liberdade não é algo como "dar livre vazão" aos impulsos. Agir livremente, de acordo com esse referencial, não é simplesmente realizar impulsos que atendam à nossa satisfação imediata - até porque Kant (como já assinalamos), insinua que o arbítrio bruto opera, principalmente, a partir de impulsos sensiveis e de forma patológica.

O que nos traz de volta ao pensamento freudiano. A clínica psicanalítica não teve a intenção de fundar uma teoria ética ou uma Filosofia Política. Contudo, os seus pressupostos que passaram por uma teoria dos sonhos - A interpretação dos sonhos (1900) -, a formação e o desenvolvimento da sexualidade - Três ensaios para uma teoria sexual (1905) -, chegando mesmo a utilizar chaves de leitura que viriam depois aproximá-la tanto da Antropologia como da Sociologia: Totem e tabu (1913) e O mal-estar da civilização (1930), atraíram os olhares de leitores mais inclinados à especulação filosófica, pois em todos esses momentos o choque entre os princípios de prazer e de realidade estavam presentes.

Se considerarmos o princípio de prazer como um impulso mais primal da mente humana para se livrar de suas tensões internas, esse seria guiado - mecanicamente, pode-se dizer - pelos impulsos biológicos, de modo que uma leitura desatenta igualaria tal condição à autonomia, pois brotaria do próprio indivíduo, sem depender de móbiles externos.

Mas já indicamos que isso não se iguala ao conceito de autonomia, afinal, o pensamento kantiano confere uma dose de "exterioridade" aos impulsos sensíveis, muito embora pertencam ao domínio do corporal, são vistos como arbítrio bruto, carentes do modelamento, das restrições racionais. Não são - os impulsos sensíveis -genuinamente independentes e, desta forma, heteronômicos.

Para o fundador da Psicanálise, o princípio de realidade opera estabelecendo uma redistribuição das catexias internas da mente, construindo um modus operandi que se afasta do arco-reflexo desprazer-prazer, embora mesmo seguindo essa busca para se evitar o desprazer, fará de modo cada vez mais elaborado, complexo, adiando a descarga das tensões, abrindo espaço para uma adaptação estratégica ao meio.

Tanto no domínio da Psicanálise como na filosofia prática kantiana há uma dimensão constritiva face às demandas do mundo sensível.

A teoria freudiana não aborda diretamente o problema da liberdade, no entanto, ao longo dos anos, Freud constatou que significativa quantidade de enfermidades psíquicas derivava do conflito entre as diferentes instâncias - sistemas - que compõem a mente humana, 
fundamentalmente o conflito entre os princípios de realidade e de prazer, mais precisamente da inabilidade da mente em, algumas ocasiões, lidar com situações vividas; ou ainda, de forma mais técnica dentro desse escopo teórico, o processo secundário - princípio de realidade - não consegue levar a bom termo a reorientação das catexias internas da mente, as quais geradas por determinada ocasião ou vivência. O trauma psíquico acaba por ser uma solução provisória e emergencial que a mente desenvolve como defesa diante de uma situação intolerável ${ }^{1}$ esse arranjo de coisas mantinha o paciente em uma condição de sofrimento.

Uma das primeiras pistas de Freud, quanto ao tratamento clínico psicanalítico, é que esse sofrimento poderia ser aliviado se o paciente se apropriasse ou reelaborasse o conteúdo das vivências desprazerosas; algo como reorganizar melhor aquele primeiro arranjo feito pela mente diante da vivência bruta. Há algo de "racionalização" nesse processo, de empoderamento afetivo do paciente sobre os fatos de sua vida.

Então, encontramos também uma "lógica de constrição" no funcionamento da mente? Se olharmos a questão pelo ângulo freudiano, a resposta tem algumas nuances.

Essa constrição, ou contenção, que na proposta kantiana se mostra explícita, em Freud se modifica em alguns aspectos fundamentais - uma vez que, embora pareçam chegar a um ponto teórico comum, a diferença no caminho trilhado também tem muito a ensinar.

O "empoderamento" do indivíduo no que se refere ao seu psiquismo, não é pleno, nem pode sê-lo, se assumido todos os aspectos das propostas psicanalíticas.

Ainda nos primórdios da formação da teoria psicanalítica, Freud atendeu um caso que ficou célebre na literatura dessa área, o de sua paciente Anna $O$, quem, então jovem, desenvolvera uma cegueira de origem histérica, dado um "choque emocional" ligado diretamente à forma como ficou ciente da morte do pai. Esse e outros casos aparecem documentados por Freud nos Estudos sobre a histeria (1893-1895) (BREUER; FREUD, [20--?a]).
Tudo isso graças à ideia de inconsciente, conceito que na Psicanálise também é descritivo de um dos sistemas do aparelho anímico, dado que não descreve algo que vem de fora do indivíduo, mas que é parte constitutiva fundamental do mesmo. No ângulo kantiano, a sua filosofia transcendental coloca a série causal infinita no domínio da coisa em si, para além daquilo que pode ser conhecido pela experiência; sua filosofia prática se posiciona dentro do campo que podemos conhecer, e mais, passa a abrir espaço para fundar um parâmetro de moralidade que tem na autonomia do indivíduo um de seus principais alicerces. $E$ isso tudo assim o é porque Kant confere à racionalidade prática uma potência maior que o controle dos impulsos via processo secundário, que em uma leitura ao modo Freud jamais conferiria.

Embora a teoria ética kantiana reconheça que há impulsos para basearmos as nossas ações nos objetos - arbítrio bruto -, e não nos imperativos universais da razão - arbítrio livre -, o "tom" geral da obra desse filósofo é de que isso - controle racional - pode ser alcançado afiando a nossa vontade, com disciplina, ou seja, ceder à heteronomia é quase como um gesto de fraqueza ou, quiçá, de preguiça.

Na Psicanálise freudiana o "tom" é completamente outro - talvez seja um dos elementos que faça com que o saber de Freud atraia o olhar dos filósofos. Afinal, no escopo freudiano, o "escolher", "empoderar-se" segue uma trilha mais acidentada. A prova mais óbvia disso é a condição clínica da elaboração e aplicação do próprio corpo teórico. Os pressupostos teóricos psicanalíticos aqui já destacados nos apresentam um indivíduo que não é plenamente senhor de si, e isso não se deve a "tentações do mundo sensível", constitucionalmente, às exigências biológicas ao psíquico, mas passam pelo sistema inconsciente, buscando alcançar o mundo por meio das ações motoras. Em um esforço para obter maior êxito, as forças - catexias - dessas demandas são contidas, ou melhor, redirecionadas para que a ação tenha um resultado mais condizente. Dito de outra forma, o ego (eu) não gera catexias próprias, podendo, no máximo, 
acumular a energia advinda de outros sistemas para distribuí-la com "mais sabedoria".

Se o ego não gera por si energia e depende da energia de outro - do id -, então qual é o seu papel nessa dinâmica? Como já dissemos, a função do eu consciente é mais "gerir" e "orientar" os impulsos e, nesse ínterim, passar longe do papel de "senhor absoluto do processo", de uma liderança forte frente às exigências de outros sistemas da mente. É, pois, uma expectativa mais modesta sobre o papel da consciência racional na vida anímica - é claro que a racionalização, elaboração dos afetos por caminhos mais estratégicos, torna-se igualmente importante; mas ainda assim, falha.

No escopo freudiano, a "falha" em se levar a elaboração dos afetos a um bom termo não deriva somente em uma conduta moralmente questionável - sob os parâmetros de determinadas sociedades em certa época -, de modo que a falha ocasiona sofrimento.

A clínica não existe apenas para erigir uma teoria sobre a melhor ação na sociedade, mas para buscar auxiliar o indivíduo que padece. Tal padecimento pode ser mitigado com o auxílio da terapia que, de um modo simplificado, implica em o paciente buscar espelhamento por meio do terapeuta - deixamos de lado certas sutilezas na aplicação da técnica analítica -, tal como um reforço para a capacidade de o paciente racionalizar/reelaborar os seus afetos - em casos clínicos, somente esse auxílio externo pode abrir caminho para a cura.

Podemos afirmar que Freud, no fundo, era um racionalista? Sim, se considerarmos que fora um racionalista à sua maneira, reconhecendo o quão limitado é o poder da consciência e frágil é o seu equilíbrio; ainda assim - e por isso -, optamos pela Psicanálise freudiana neste exercício reflexivo, dado que o indivíduo deveria buscar tal evolução; desenvolver, aprimorar, mesmo que a duras penas, esse conhecimento sobre si, com o qual conseguisse cada vez melhor lidar com a vida.

Não para menos, encontramos uma passagem célebre em seu texto, defendendo que uma das intenções terapêuticas da Psicanálise seria o fortalecimento do ego, a fim de ampliar o seu campo de percepção e expandir a sua organização, de maneira a poder se assenhorear de novas partes do id - onde estava o id, estará o ego (FREUD, [20--?e], p. 55).

Se em Kant temos uma filosofia que elogia e esclarece que devemos viver com autonomia, em Freud figura um saber que reconhece os obstáculos, mas sinaliza com a resiliência em se buscar por essa autonomia, característica esta que ambos os autores poderiam concordar ser um caminho para a vivência de liberdade.

Sabemos que muitas questões ficaram além dos limites deste capítulo, de modo que esperamos torná-lo o início de novas contribuições que, entre outros temas, coloquem em pauta $o$ exercício reflexivo de comparar domínios distintos de pensamento.

Finalmente, entendemos que na sua busca por novas respostas, a Filosofia teria muito a ganhar reformulando as velhas perguntas.

\section{Referências}

ARAÚJO, A. M. Estética e moralidade em Kant: a relação entre o sublime e o sentimento moral na crítica da faculdade do juízo. 2012. Dissertação (Mestrado em Filosofia)-Departamento de Filosofia da Pontifícia Universidade Católica do Rio de Janeiro, Rio de Janeiro, 2012

BREUER, J.; FREUD, S. Edição standard brasileira das obras psicológicas completas de Sigmund Freud. Estudos sobre a histeria (1893-1895). v. 2. [S.l.: s.n., 20--?a].

Edição standard brasileira das obras psicológicas completas de Sigmund Freud. Comunicação preliminar (1893-1895). v. 2. [S.l.: s.n., 2O--?b].

Edição standard brasileira das obras psicológicas completas de Sigmund Freud. Narcisismo: uma introdução (1914). v. 14. [S.l.: s.n., 20--?c].

FERRY, L. Kant: uma leitura das três "críticas". Trad. Karina Jannini. 3. ed. Rio de Janeiro: Difel, 2012.

FREUD, S. Projeto de uma psicologia. Trad. Osmry Faria Gabbi Jr. Rio de Janeiro: Imago, 1995. (Col. Obras Isoladas de Freud). 
A interpretação dos sonhos. v. 1-2. ed. rev. Rio de Janeiro: Imago, 1988.

Obras completas de Sigmund Freud. Três ensaios para uma teoria sexual (1905). v. 7. [S.l.: s.n., 20--?a].

Obras completas de Sigmund Freud. Totem e tabu (1913). v. 13. [S.l.: s.n., 20--?b].

Obras completas de Sigmund Freud. Sobre - narcisismo: uma introdução (1914). v. 14. [S.l.: s.n., 20--?c].

Obras completas de Sigmund Freud. O ego e o id (1923). v. 19. [S.l.: s.n., 20--?d].

Obras completas de Sigmund Freud. Novas conferências introdutórias de Psicanálise (1933 [1932]). v. 22. [S.l.: s.n., 20--?e].
KANT, I. A crítica da razão prática. Trad. Valério Rohden. São Paulo: Folha de S.Paulo, 2015.

Fundamentação da metafísica dos costumes e outros escritos. Trad. Leopoldo Holzabch. São Paulo: Martin Claret, 2005.

A crítica da razão pura. Trad. Manuela Pinto dos Santos; Alexandre Fradique Morujão. Lisboa: Edição da Fundação Calouste Gulbenkian, 1994.

MEZAN, R. Freud: a trama dos conceitos. 3. ed. São Paulo: Perspectiva, 1991.

RENAUT, A. O indivíduo: reflexão acerca da filosofia do sujeito. Trad. Elena Gaidano. 2. ed. Rio de Janeiro: Difel, 2004. 